\title{
Características produtivas de novilhas submetidas à restrição alimentar e dieta suplementada com vitaminas D e E
}

\author{
Marina Parrili(1), Sueli Akemi Matsuhara( ${ }^{(1)}$, Mário De Beni Arrigoni(1), Cyntia Ludovico Martins ${ }^{(2)}$, \\ Danilo Domingues Millen ${ }^{(3)}$, Rodrigo Dias Lauritano Pacheco ${ }^{(1)}$, Luis Marcelo Nave Sarti ${ }^{(1)}$, \\ Samira Rodrigues Baldin ${ }^{(1)}$ e Fernando Salvador Parra(1)
}

\begin{abstract}
(1)Universidade Estadual Paulista (Unesp), Faculdade de Medicina Veterinária e Zootecnia (FMVZ), Departamento de Melhoramento e Nutrição Animal, Caixa Postal 560, CEP 18618-000 Botucatu, SP. E-mail: mariparrili@hotmail.com, suelimatsuhara@yahoo.com.br, arrigoni@fmvz.unesp.br, pachecozoo@yahoo.com.br, Im.sarti@hotmail.com, samirabaldin@yahoo.com.br, fernandoparra@zootecnista.com.br (2)Unesp, FMVZ, Departamento de Produção e Exploração Animal. E-mail: cludovico@fmvz.unesp.br (3)Unesp, Rodovia Comandante João Ribeiro de Barros, Km 651, CEP 17900-000 Dracena, SP. E-mail: danilomillen@dracena.unesp.br
\end{abstract}

Resumo - O objetivo deste trabalho foi avaliar os efeitos da restrição alimentar e de dieta de suplementação com vitaminas D e E sobre o desempenho e características de carcaça de novilhas Canchim. Vinte e quatro fêmeas, com peso vivo inicial médio de 251,95 $18,49 \mathrm{~kg}$, foram distribuídas em quatro tratamentos: alimentação em quantidade restrita e não restrita, com e sem suplementação de vitaminas D e E. Utilizou-se o delineamento inteiramente casualizado, em arranjo fatorial $2 \times 2$, com seis repetições. Os animais com alimentação restrita receberam, por 48 dias, $70 \%$ da dieta fornecida ao grupo de alimentação não restrita. Após o período de restrição (peso médio de $300,10 \mathrm{~kg}$ ), eles voltaram a receber ração à vontade por mais 77 dias, até atingirem peso de abate de $380 \mathrm{~kg}$. As avaliações foram feitas ao final dos períodos de restrição e de realimentação. Não foi observado efeito da restrição alimentar sobre o desempenho animal. Novilhas que não receberam suplementação vitamínica apresentaram maiores índices de fragmentação miofibrilar, luminosidade e mastigabilidade, e menor força de cisalhamento. A restrição alimentar não afeta o desempenho nem as características de carcaça das novilhas Canchim, e a suplementação com vitaminas D e E não melhora a qualidade da carne.

Termos para indexação: Bos taurus, Canchim, confinamento, crescimento compensatório, desempenho, terminação.

\section{Productive traits of heifers subjected to feed restriction and diet supplemented with vitamins $D$ and $E$}

\begin{abstract}
The objective of this work was to evaluate the effects of feed restriction and vitamin D and E supplementation on the performance and carcass traits of Canchim heifers. Twenty-four Canchim heifers with initial body weight of $251.95 \pm 18.49 \mathrm{~kg}$ were distributed in four treatments: restricted and unrestricted quantity of feeding, with or without vitamin $\mathrm{D}$ and $\mathrm{E}$ supplementation. A completely randomized experimental design was used in a $2 \times 2$ factorial arrangement, with six replicates. Animals with restricted feeding received, for 48 days, $70 \%$ of the feed offered for the group of unrestricted feeding. After the restriction period, animals (300.10 kg mean weight) receive unrestricted feeding for more 77 days, until they reach the slaughter weight of $380 \mathrm{~kg}$. The evaluations were made at the end of the periods of restriction and refeeding. No effect of feed restriction was observed on animal performance. Heifers that did not receive supplementation with vitamin D and $\mathrm{E}$ had greater indexes of myofibril fragmentation, luminosity, and chewing score, and lower shear force. Feed restriction does not affect the performance and carcass traits of Canchim heifers, and vitamin D and $\mathrm{E}$ supplementation does not improve meat quality.
\end{abstract}

Index terms: Bos taurus, Canchim, feedlot, compensatory growth, performance, finishing.

\section{Introdução}

A engorda de novilhas em confinamento é uma prática muito utilizada atualmente. Segundo levantamento conduzido por Millen et al. (2009), $21,8 \%$ dos produtores, clientes dos nutricionistas que participaram da pesquisa, alimentam novilhas por 68 dias em média, até elas atingirem peso vivo final médio de $364,1 \mathrm{~kg}$. Essa prática de engordar novilhas, normalmente, é realizada estratégicamente, por permitir rápido giro de capital e valorização pela qualidade das carcaças. 
Em razão do menor peso à maturidade, as novilhas depositam mais tecido adiposo do que animais machos, o que reduz o desempenho produtivo. Uma alternativa viável para reduzir a deposição excessiva de gordura na carcaça na terminação de novilhas é explorar o crescimento compensatório. O uso estratégico de um período inicial de restrição alimentar, com posterior exploração do ganho compensatório, é utilizado com o intuito de aumentar o peso das novilhas à maturidade (Sainz et al., 1995), com menor fornecimento de energia e consequente atraso no início da fase de deposição de gordura. Segundo os autores, essa prática pode melhorar o desempenho produtivo e reduzir o tempo de alimentação e a idade ao abate de fêmeas. De 2008 a 2010, o abate de fêmeas representou 45,3\% em relação ao total de bovinos abatidos no Brasil (Anualpec, 2011), o que mostra a relevância de estudos para aumentar a eficiência produtiva de fêmeas.

Porém, algumas características de qualidade da carcaça e da carne podem ser afetadas negativamente com a adoção de estratégias de restrição alimentar por determinado período de tempo. Hammond (1956) apresentou o conceito de que, após os bovinos passarem por severa restrição alimentar, a recuperação provoca aumento de tecido conjuntivo, com prejuízo para a maciez da carne. Entretanto, a utilização de tecnologias que melhoram os atributos de qualidade da carne, como a suplementação de vitaminas D e E, podem auxiliar na manutenção ou na melhoria de características como maciez e durabilidade do produto (Arnold et al., 1992; Rider Sell et al., 2004).

O objetivo deste trabalho foi avaliar os efeitos da restrição alimentar e de dieta de suplementação com vitaminas $\mathrm{D}$ e $\mathrm{E}$ sobre o desempenho e características de carcaça e carne de fêmeas jovens da raça Canchim.

\section{Material e Métodos}

O trabalho foi realizado entre julho e novembro de 2008, de acordo com as normas da comissão de ética no uso de animais, da Faculdade de Medicina Veterinária e Zootecnia, da Universidade Estadual Paulista (Unesp), Botucatu, SP.

Foram utilizadas 24 fêmeas da raça Canchim, desmamadas aos sete meses de idade, com peso vivo inicial médio de $251,95 \pm 18,49 \mathrm{~kg}$, provenientes de sistema de alimentação privativa - permaneciam junto às mães, mas se alimentavam em cocho em área privada, onde iniciaram o consumo de ingredientes concentrados, como milho finamente moído e farelo de algodão, desde dois meses de idade. Nas instalações de confinamento, os animais foram mantidos em baias de $25 \mathrm{~m}^{2}$ individuais totalmente cobertas com $5 \mathrm{~m}$ de cocho por animal.

O experimento foi composto de quatro tratamentos: alimentação restrita por quantidade, sem suplementação de vitaminas D e E; alimentação restrita por quantidade, com suplementação de vitaminas D e E; alimentação à vontade, sem suplementação de vitaminas $\mathrm{D} e$ E; e alimentação à vontade, com suplementação de vitaminas $\mathrm{D}$ e E. Utilizou-se o delineamento inteiramente casualizado, em arranjo fatorial $2 \times 2$, com seis repetições e parcela experimental constituída de um animal.

Antes do início do experimento, os animais foram pesados e adaptados às baias e às dietas por 21 dias. Após o período de adaptação, os animais do grupo de alimentação não restrita receberam a dieta à vontade. Os animais do grupo de alimentação restrita receberam, $70 \%$ da quantidade da mesma dieta fornecida ao outro grupo. Quando todos os animais do estudo atingiram peso vivo médio de, aproximadamente, $300 \mathrm{~kg}$, eles foram submetidos ao período de realimentação. Assim, após o período de restrição, que durou 48 dias, todas as novilhas receberam a ração à vontade até atingirem peso vivo médio de abate em torno de $380 \mathrm{~kg}$, segundo metodologia proposta por Sainz et al. (1995). O período de realimentação teve a duração de 77 dias.

A ração fornecida foi formulada conforme o Cornell Net Carbohydrate and Protein System (2000) (Tabela 1). A quantidade de ração fornecida e as sobras foram pesadas diariamente, e as rações foram amostradas semanalmente para determinação dos teores de matéria seca, proteína bruta, extrato etéreo, cinzas, cálcio e fósforo, avaliados conforme Horwitz (2006), e fibra em detergente neutro (FDN) de acordo com Goering \& Van Soest (1970).

Os animais foram monitorados no início e no final de cada período (restrição e realimentação), por meio de ultrassom Aloka SSD-1100 Flexus RTU, com 17,2 cm e probe de 3,5 MHz (Aloka Co. Ltd., Tóquio, Japão), conforme Greiner et al. (2003). Foram avaliadas a espessura de gordura subcutânea (EGS) e a área de olho de lombo (AOL) sobre o músculo longissimus (contra-filé), e a espessura de gordura na picanha 
(EGP8) sobre o músculo biceps femoris (picanha). Foram calculados, para cada período, restrição e realimentação, e os ganhos diários em AOL, EGS e EGP8. Também no início e no final de cada período, as novilhas foram pesadas após jejum de sólidos de 16 horas, para monitoração do ganho diário de peso vivo. A ingestão de massa de matéria seca foi mensurada diariamente, e foram calculados dados referentes ao desempenho, como conversão alimentar, e ingestão de massa de matéria seca, expressa em quilogramas e em percentagem do peso vivo.

As doses diárias e o período de oferecimento das vitaminas $\mathrm{D}$ e $\mathrm{E}$ foram estabelecidos de acordo com Swanek et al. (1999) e Arnold et al. (1992). A suplementação com vitamina $\mathrm{D}_{3}$ foi de $7,5 \times 10^{6} \mathrm{UI}$ por animal por dia, durante 18 dias antes do abate, e a suplementação com vitamina $\mathrm{E}$ foi de 1.838 UI por animal por dia, durante 43 dias antes do abate.

Os animais foram abatidos em frigorífico comercial, de acordo com os procedimentos de abate humanitário, conforme legislação brasileira vigente. Logo após o abate, depois da esfola e evisceração dos animais, o fígado e a gordura visceral foram coletados da

Tabela 1. Composição nutricional das dietas fornecidas às novilhas Canchim nas fases de adaptação e experimental.

\begin{tabular}{lrr}
\hline \multirow{2}{*}{ Item } & \multicolumn{2}{c}{ Período } \\
\cline { 2 - 3 } & Adaptação & Experimental \\
\hline Ingredientes (\% de MS) & 25,30 & 6,76 \\
Silagem de milho & 18,07 & 9,66 \\
Bagaço de cana cru & 15,67 & 41,06 \\
Silagem de grão úmido de milho & 20,48 & 32,85 \\
Milho em grão quebrado & 18,07 & 7,74 \\
Farelo de soja & 2,41 & 1,93 \\
Suplemento mineral ${ }^{(1)}$ & & \\
\hline Conteúdo nutricional & 56,00 & 68,00 \\
Matéria seca (\% da matéria natural) & 68,00 & 80,00 \\
Nutrientes digestíveis totais (\% de MS) & 0,98 & 1,32 \\
Energia líquida para ganho (Mcal kg-1 de MS) & 41,00 & 61,00 \\
Total de carboidratos não fibrosos (\% de MS) ${ }^{(2)(3)}$ & 39,00 & 56,00 \\
Amido (\% de MS) ${ }^{(2)}$ & 16,00 & 13,00 \\
Proteína bruta (\% de MS) & 3,20 & 4,60 \\
Extrato etéreo (\% de MS) & 36,70 & 20,10 \\
Fibra em detergente neutro (\% de MS) & 0,62 & 0,45 \\
Cálcio (\% de MS) & 0,41 & 0,38 \\
Fósforo (\% de MS) & & \\
\hline
\end{tabular}

(1) $\mathrm{O}$ suplemento continha $30 \%$ de ureia; $26,7 \%$ de Ca; $5,3 \%$ de $\mathrm{P} ; 10,9 \%$ de Na; $1,5 \%$ de S; 2.600 ppm de Zn; 1.300 ppm de Mn; 1.032 ppm de Cu; $45 \mathrm{ppm}$ de I; 15 ppm de Se; 154 ppm de Cu, 2.500 ppm de Fe; e $1.500 \mathrm{mg}$ de monensina sódica, por quilograma de suplemento. ${ }^{(2)}$ Estimado de acordo com o Cornell Net Carbohydrate and Protein System (2000). ${ }^{(3)}$ Carboidratos não fibrosos, $\mathrm{CNF}=100$ - (proteína bruta + extrato etéreo + fibra em detergente neutro + cinzas) carcaça e pesados. As carcaças foram divididas em duas meias carcaças e, desta forma, foram pesadas para obtenção do peso de carcaça quente (PCQ). Os dados de peso do figado e gordura visceral foram expressos em quilogramas e como percentagem do PCQ. O rendimento de carcaça foi calculado a partir do PCQ dividido pelo peso vivo final do animal em jejum, obtido no confinamento antes do embarque para o frigorífico. Os rendimentos de dianteiro e traseiro foram calculados pela divisão dos pesos em quilogramas pelo PCQ.

Após o abate, as carcaças foram resfriadas por 24 horas a $0^{\circ} \mathrm{C}$. Após o resfriamento, seis amostras do músculo longissimus, entre a $9^{a}$ e a $13^{\text {a }}$ costelas, com $2,54 \mathrm{~cm}$ de espessura cada, foram retiradas da meia carcaça esquerda, etiquetadas, embaladas a vácuo, congeladas a $-20^{\circ} \mathrm{C}$ e transportadas para o Laboratório de Carnes da Unesp, Campus de Botucatu, onde foram armazenadas para futuras análises sensoriais e laboratoriais.

As avaliações sensoriais foram conduzidas de acordo com Jenkins et al. (2011), com dez provadores treinados, em quatro seções de análises. O músculo longissimus foi avaliado com uso de escalas estruturadas de um a nove pontos, quanto à maciez ( 1 , extremamente macio; 9, extremamente duro) e à suculência (1, extremamente suculento; 9, extremamente seco). Para a mastigabilidade, foi utilizada escala não estruturada de nove pontos, que variou de "elástica, borrachenta, difícil de deglutir" a "desintegra facilmente na boca, fácil de deglutir".

Para se mensurar a cor do músculo longissimus, foi utilizado o método de Hunter (Montgomery et al., 2004a) e os denominados Cieluv, recomendado para avaliar luzes com grande diferença de cor, e Cielab, recomendado para avaliar objetos com pequena diferença de cor. Para as mensurações, utilizou-se o aparelho Minolta Chroma Meter Measuring Head, modelo CR-410 (Konica Minolta, Osaka, Japão). As amostras foram desembaladas e expostas ao ar por 30 min e, em seguida, foram realizadas três medidas, em três diferentes pontos, tendo-se considerado como dado final a média dos três valores medidos para luminosidade $\left(\mathrm{L}^{*}\right)$, intensidade do vermelho $\left(\mathrm{a}^{*}\right)$ e intensidade do amarelo (b*).

A avaliação da marmorização da carne também foi feita nas amostras retiradas do longissimus, entre a $12^{\text {a }}$ e 13 ${ }^{\text {a }}$ costela, e foi coduzida conforme United States 
Department of Agriculture (1989), adaptado porAlbrecht et al. (2006), que descreve o escore de marmoreio em escala de seis pontos, em que 1 significa praticamente sem marmorização e 6 significa altamente marmorizado. Fotos-padrão serviram como referência para o escore e, por se tratar de análise subjetiva, um grupo de três pessoas treinadas avaliou as amostras, e o escore final foi representado pela média desses três escores.

Para a determinação da força de cisalhamento, as amostras do músculo longissimus, retiradas entre a $12^{\mathrm{a}} \mathrm{e}$ a $13^{\mathrm{a}}$ costela, foram maturadas por sete dias e submetidas a análise conforme Wheeler et al. (2002), por meio do medidor de força de cisalhamento Warner-Bratzler (G-R Electric Manufacturing Company, Manhattan, Kansas, Estados Unidos).

Amostras do músculo longissimus entre a $9^{\mathrm{a}}$ e a $10^{\mathrm{a}}$ costela, sem a gordura de cobertura, foram utilizadas para as análises de lipídeos totais. A percentagem de lipídeos totais foi determinada em amostras cruas e moídas de carne (aproximadamente 3,5 g), pelo método proposto por Starke et al. (2010).

Para a análise do índice de fragmentação miofibrilar, foram utilizados $4 \mathrm{~g}$ de amostra fresca livre de gordura e de tecido conectivo do músculo longissimus, resfriados por 24 horas, retirados da região entre a $12^{\text {a }}$ e 13a costela. O índice de fragmentação miofibrilar foi determinado conforme Kerth et al. (2003).

As concentrações de vitaminas D e E foram também foram determinadas nas amostras do músculo longissimus (50 g), por cromatografia líquida de alta eficiência após hidrólise e quantificação por detector de UV-VIS (Jasco, Great Dunmow. Essex, Inglaterra), conforme Montgomery et al. (2004b), no laboratório da SGB Consultoria, em Pedreira, SP. O procedimento das análises foi o mesmo para as vitaminas D e E, por se tratarem ambas de vitaminas lipossolúveis.

Os dados referentes às medidas de ultrassom e ao desempenho em confinamento foram examinados por meio de análise de variância, com medidas repetidas no tempo e uso do Proc Mixed do SAS (SAS Institute, 2003). O modelo incluiu os efeitos da restrição alimentar (alimentação restrita e alimentação não restrita), dos diferentes períodos de avaliação (restrição e realimentação) e a interação entre restrição alimentar e períodos de avaliação. Os dados referentes às características de carcaça (pesos da gordura visceral e fígado, PCQ, rendimentos de carcaça, dianteiro e traseiro) foram analisados por análise de variância por meio do Proc GLM do SAS. O modelo incluiu somente o efeito da restrição alimentar. Os dados referentes às características de carne foram analisados em arranjo fatorial 2x2, com uso do Proc GLM e do teste de Tukey, a $5 \%$ de probabilidade, para comparação de médias. $\mathrm{O}$ modelo incluiu os efeitos da restrição alimentar (alimentação restrita e alimentação não restrita), adição ou não de vitamina $\mathrm{D}$ e E e a interação entre eles.

\section{Resultados e Discussão}

Não houve efeito significativo dos fatores restrição alimentar e períodos de alimentação sobre as variáveis de desempenho (Tabela 2). No entanto, houve interação significativa entre restrição alimentar e períodos, para as seguintes variáveis de desempenho: ingestão de matéria seca, expressa em quilogramas; ingestão de matéria seca, expressa em percentagem do peso vivo; ganho de peso médio diário; e conversão alimentar. Novilhas do grupo de alimentação restrita apresentaram menores ingestões de matéria seca, tanto em quilogramas quanto em percentagem do peso vivo, e pior conversão alimentar durante o período de restrição, em relação ao período de realimentação (Tabela 3); entretanto, no período de realimentação, as novilhas do grupo de alimentação restrita tiveram maior ingestão de matéria seca e melhor conversão alimentar do que animais do grupo de alimentação não restrita. No período de restrição, o grupo de alimentação não restrita, obviamente, apresentou maior ganho de peso médio diário que o grupo de novilhas com alimentação restrita; no entanto, no período de realimentação, não foi encontrada diferença significativa entre os tratamentos.

Dessa forma, mesmo após os animais do grupo de alimentação restrita terem passado por período de restrição alimentar, eles conseguiram compensar o desempenho (ingestão de matéria seca e conversão alimentar) no período de realimentação, o que fez com que não fossem observadas diferenças significativas entre os tratamentos quanto ao peso vivo final (Tabela2). Estes resultados corroboram os de Lawrence \& Pearce (1964), que relataram que as mudanças ocorridas no período de restrição alimentar são reversíveis, pois, durante a realimentação compensatória, restabelecemse os pesos dos bovinos e recompõem-se as características desejáveis das carcaças.

Quando a restrição alimentar ocorre por limitação da quantidade de uma dieta de alta qualidade (restrição 
quantitativa), há relatos de elevação da ingestão de massa de matéria seca após a restrição, conforme constatado no presente trabalho (Tabela 3 ), de modo que esse aumento pode explicar porção significativa do ganho de peso no período de realimentação, e melhorar a conversão alimentar do grupo de animais que passaram por restrição (Ryan, 1990). Segundo Sainz et al. (1995), o aumento do trato gastrintestinal, em relação ao peso vivo, ajuda a explicar aumentos de consumo, seja pelo maior espaço ou pela maior capacidade digestiva. Vale ressaltar que animais que sofrem restrição entram na fase de realimentação com menor tamanho e, assim, têm menor necessidade de mantença, o que acarreta proporção maior de energia destinada ao ganho de peso.

Não houve efeito significativo da restrição alimentar sobre a maioria das variáveis de características de carcaça (Tabela 2), com exceção do rendimento de traseiro e gordura visceral (percentagem do PCQ), em que novilhas do grupo alimentação restrita apresentaram resultados significativamente maiores. Houve interação significativa entre restrição alimentar e períodos de alimentação, quanto ao ganho diário em AOL e EGP8. No período de restrição, novilhas do grupo alimentação não restrita apresentaram maior $(\mathrm{p}<0,05)$ ganho diário de $\operatorname{AOL}\left(0,20 \mathrm{~cm}^{2}\right)$ que as do grupo com alimentação restrita $\left(0,11 \mathrm{~cm}^{2}\right)$; no entanto, nenhuma diferença foi observada entre os tratamentos no período de realimentação $\left(0,14 \mathrm{~cm}^{2}\right)$. No período de realimentação, o grupo que passou por alimentação restrita apresentou ganho diário em EGP8 significativamente maior $(0,036 \mathrm{~mm})$ que o grupo de alimentação não restrita $(0,022 \mathrm{~mm})$, mas não observouse diferença significativa, no período de restrição, entre os grupos de alimentação restrita $(0,016 \mathrm{~mm})$ e não restrita $(0,025 \mathrm{~mm})$. Todavia, observou-se efeito principal significativo do período de alimentação sobre a maioria das características de carcaça, com exceção dos ganhos diários em AOL, EGS e EGP8.

Tabela 2. Efeito da restrição alimentar e dos períodos de avaliação sobre o desempenho e características de carcaça de novilhas da raça Canchim(1).

\begin{tabular}{|c|c|c|c|c|c|}
\hline \multirow[t]{2}{*}{ Variável } & \multicolumn{2}{|c|}{ Regime alimentar } & \multicolumn{2}{|c|}{ Período de avaliação } & \multirow[t]{2}{*}{ EPM } \\
\hline & Com restrição & Sem restrição & Restrição & Realimentação & \\
\hline \multicolumn{6}{|l|}{ Desempenho } \\
\hline Peso vivo inicial (kg) & 257,80 & 252,80 & $255,30 b$ & $300,10 \mathrm{a}$ & 19,40 \\
\hline Peso vivo final $(\mathrm{kg})$ & 377,10 & 383,20 & $300,10 b$ & $380,20 \mathrm{a}$ & 30,60 \\
\hline Ganho de peso diário $(\mathrm{kg})$ & 1,04 & 0,95 & 0,93 & 1,04 & 0,17 \\
\hline Ingestão de matéria seca (kg) & 6,70 & 7,06 & 5,48 & 7,61 & 0,21 \\
\hline Ingestão de matéria seca (\% do PV) & 2,12 & 2,24 & 1,98 & 2,24 & 0,05 \\
\hline Conversão alimentar $\left(\mathrm{kg} \mathrm{kg}^{-1}\right)$ & 6,81 & 6,76 & 5,84 & 7,46 & 0,23 \\
\hline \multicolumn{6}{|l|}{ Características de carcaça } \\
\hline Área de olho de lombo inicial $\left(\mathrm{cm}^{2}\right)$ & 48,39 & 45,58 & $46,98 b$ & $54,35 \mathrm{a}$ & 6,63 \\
\hline Área de olho de lombo final $\left(\mathrm{cm}^{2}\right)$ & 64,51 & 66,08 & $54,35 b$ & $65,29 a$ & 8,06 \\
\hline Ganho diário de área de olho de lombo $\left(\mathrm{cm}^{2}\right)$ & 0,13 & 0,16 & 0,15 & 0,14 & 0,05 \\
\hline Espessura de gordura subcutânea inicial (mm) & 1,59 & 1,40 & $1,50 \mathrm{~b}$ & $2,43 \mathrm{a}$ & 0,33 \\
\hline Espessura de gordura subcutânea final (mm) & 4,20 & 4,05 & $2,43 b$ & $4,12 \mathrm{a}$ & 1,12 \\
\hline Ganho diário de espessura de gordura subcutânea (mm) & 0,021 & 0,021 & 0,019 & 0,022 & 0,009 \\
\hline Espessura de gordura na picanha 8 inicial $(\mathrm{mm})$ & 2,29 & 1,83 & $2,06 \mathrm{~b}$ & $3,06 \mathrm{a}$ & 0,59 \\
\hline Espessura de gordura na picanha 8 final (mm) & 5,83 & 4,72 & $3,06 \mathrm{~b}$ & $5,27 \mathrm{a}$ & 1,68 \\
\hline Ganho diário de espessura de gordura na picanha $8(\mathrm{~mm})$ & $0,028 \mathrm{a}$ & $0,023 b$ & 0,021 & 0,029 & 0,012 \\
\hline Peso de carcaça quente $(\mathrm{kg})$ & 199,90 & 207,30 & - & - & 18,50 \\
\hline Rendimento de carcaça (\%) & 53,00 & 54,02 & - & - & 1,27 \\
\hline Rendimento do dianteiro (\%) & 36,84 & 37,57 & - & - & 0,94 \\
\hline Rendimento do traseiro (\%) & $51,59 \mathrm{a}$ & $50,46 b$ & - & - & 0,91 \\
\hline Gordura visceral $(\mathrm{kg})$ & 6,39 & 5,23 & - & - & 1,42 \\
\hline Gordura visceral ( $\%$ do peso de carcaça quente) & $3,19 \mathrm{a}$ & $2,54 \mathrm{~b}$ & - & - & 0,71 \\
\hline Fígado $(\mathrm{kg})$ & 4,74 & 4,92 & - & - & 0,48 \\
\hline Fígado ( $\%$ do peso de carcaça quente) & 2,37 & 2,38 & - & - & 0,18 \\
\hline
\end{tabular}

${ }^{(1)}$ Médias seguidas de letras iguais, nas linhas, não diferem, pelo teste de Tukey, a 5\% de probabilidade. EPM, erro-padrão da média. 
Os resultados relacionados às características de carcaça discordam dos dados de Choat et al. (2003), que observaram o mesmo conteúdo de gordura entre animais em crescimento normal e aqueles em compensação de crescimento. Reinhardt et al. (2009) afirmaram que a composição do ganho de animais em crescimento compensatório tem maior conteúdo de gordura, o que foi observado no presente trabalho, em que novilhas do grupo de alimentação restrita apresentaram maior deposição de gordura visceral em percentagem do PCQ (Tabela 2) e maior ganho diário de EGP8 no período de realimentação, o que pode ter contribuído para o maior rendimento de traseiro, apresentado pelas novilhas que passaram por restrição alimentar.

Sainz et al. (1995) relatam que não há diferença entre grupos de animais que passam ou não por restrição alimentar, quanto à $\mathrm{AOL}$, e que o desenvolvimento muscular não é prejudicado pela restrição. Os resultados referentes à AOL estão coerentes com os dados de ganho de peso médio diário obtidos no presente trabalho, pois no período de restrição, novilhas do grupo alimentação restrita apresentaram menor ganho de peso médio diário e ganho diário de AOL, porém houve compensação quanto a este caráter, no período de realimentação. $\mathrm{O}$ crescimento muscular e, consequentemente, o desempenho não foram negativamente afetados no presente trabalho.

Com relação ao peso do fígado, Lawrence \& Pearce (1964) relataram influência considerável da restrição alimentar no aumento do fígado, na fase inicial de compensação; contudo, os autores ressaltaram que, quando se considera todo o período de realimentação, esse fator perde significativamente a importância, o que pode explicar os dados obtidos no presente trabalho (Tabela 2). Segundo Ryan (1990), o tempo de

Tabela 3. Desdobramentos dos efeitos da restrição alimentar nos períodos de avaliação, quanto a ingestão de matéria seca (IMS), ganho de peso médio diário (GP) e conversão alimentar (CA), de novilhas da raça Canchim ${ }^{(1)}$.

\begin{tabular}{lccccc}
\hline Variável & \multicolumn{2}{c}{ Com restrição } & & \multicolumn{2}{c}{ Sem restrição } \\
\cline { 2 - 3 } \cline { 6 - 7 } & Restrição & Realimentação & & Restrição & Realimentação \\
\hline IMS (kg) & $4,73 \mathrm{Bb}$ & $7,81 \mathrm{Aa}$ & & $6,23 \mathrm{Ab}$ & $7,42 \mathrm{Ba}$ \\
IMS (\% do PV) & $1,73 \mathrm{Bb}$ & $2,34 \mathrm{Aa}$ & & $2,23 \mathrm{Aa}$ & $2,15 \mathrm{Ba}$ \\
GP diário $(\mathrm{kg})$ & $0,70 \mathrm{Bb}$ & $1,11 \mathrm{Aa}$ & & $1,17 \mathrm{Aa}$ & $0,97 \mathrm{Ab}$ \\
$\mathrm{CA}\left(\mathrm{kg} \mathrm{kg}^{-1}\right)$ & $6,27 \mathrm{Ab}$ & $7,07 \mathrm{Ba}$ & & $5,41 \mathrm{Bb}$ & $7,84 \mathrm{Aa}$ \\
\hline
\end{tabular}

${ }^{(1)}$ Médias seguidas de letras iguais, minúsculas entre períodos de alimentação e maiúsculas entre restrição alimentar, não diferem, pelo teste de Tukey, a $5 \%$ de probabilidade. recuperação para os órgãos internos atingirem pesos e tamanhos normais, em relação ao peso vivo, após o fim da restrição, pode levar de 70 a 90 dias. No presente trabalho, o período de realimentação teve duração de 77 dias, o que poderia explicar a semelhança dos pesos de fígado entre animais dos grupos alimentação restrita e não restrita.

Não houve efeito da restrição alimentar sobre a maioria das variáveis de características de carne avaliadas, com exceção da maciez mensurada via painel sensorial e intensidade de cor amarela ( $\left.b^{*}\right)$, em que novilhas do grupo de alimentação restrita apresentaram carne mais macia e mais amarelada (Tabela 4). A maior intensidade de cor amarela no músculo longissimus, em animais que passaram por período de alimentação restrita, pode ser explicada pelo fato de esses animais terem apresentado EGS final semelhante e menor deposição de AOL do que novilhas que não passaram por restrição alimentar. Uma vez que não foram encontrados dados na literatura, não está claro ainda o porquê de os animais do grupo alimentação restrita terem apresentado carne mais macia do que os do grupo alimentação não restrita, via painel sensorial. No entanto, esse método é subjetivo e apresentou resultados contrastantes aos da avaliação da maciez por métodos objetivos, como o da força de cisalhamento e do índice de fragmentação miofibrilar, nos quais não foram encontradas diferenças significativas entre alimentação restrita e sem restrição.

Tabela 4. Efeito da restrição alimentar e da suplementação com vitaminas $\mathrm{D}$ e $\mathrm{E}$ nas características qualitativas da carne de novilhas da raça Canchim ${ }^{(1)}$.

\begin{tabular}{lccccccc}
\hline Característica & \multicolumn{3}{c}{ Alimentação } & & \multicolumn{2}{c}{ Vitamina } & EPM \\
\cline { 2 - 3 } & Restrita & Não restrita & & Com & Sem & \\
\hline Vitamina D (\%) & 0,06 & 0,08 & & 0,07 & 0,07 & 0,04 \\
Vitamina E (\%) & 4,80 & 5,38 & & 5,91 & 4,27 & 2,40 \\
Cor L* & 42,19 & 40,44 & & $40,05 \mathrm{~b}$ & $42,58 \mathrm{a}$ & 2,13 \\
Cor a* & 18,79 & 18,17 & & 18,23 & 18,73 & 1,50 \\
Cor b* & $10,73 \mathrm{a}$ & $9,92 \mathrm{~b}$ & & 10,07 & 10,58 & 0,70 \\
Marmoreio & 1,50 & 1,87 & & 1,75 & 1,62 & 0,48 \\
Lipídeos totais (\%) & 1,89 & 1,95 & & 1,95 & 1,89 & 0,99 \\
FC (kg) & 3,60 & 3,71 & & $3,99 \mathrm{a}$ & $3,32 \mathrm{~b}$ & 0,57 \\
IFM & 77,50 & 73,50 & & $67,60 \mathrm{~b}$ & $83,41 \mathrm{a}$ & 14,60 \\
\hline Painel sensorial & & & & & & \\
$\quad$ Maciez & $2,90 \mathrm{~b}$ & $4,30 \mathrm{a}$ & & 4,22 & 4,00 & 0,89 \\
$\quad$ Suculência & 4,90 & 4,90 & & 4,91 & 4,85 & 1,31 \\
$\quad$ Mastigabilidade & 5,50 & 5,30 & & $5,20 \mathrm{~b}$ & $5,59 \mathrm{a}$ & 1,01 \\
\hline
\end{tabular}

${ }^{(1)}$ Médias seguidas de letras iguais, nas linhas, não diferem, pelo teste de Tukey, a 5\% de probabilidade. EPM, erro-padrão da média; FC, força de cisalhamento; IFM, índice de fragmentação miofibrilar. 
Houve efeito principal significativo da suplementação de vitaminas sobre algumas características de carne avaliadas, como: luminosidade ( $\left.\mathrm{L}^{*}\right)$, força de cisalhamento, índice de fragmentação miofibrilar e mastigabilidade. Novilhas sem suplementação de vitaminas DeEtiverammaiores índices de fragmentação miofibrilar, $\mathrm{L}^{*}$ e mastigabilidade, e menor força de cisalhamento (Tabela 4). Esses resultados não estão de acordo com alguns trabalhos realizados anteriormente. Arnold et al. (1992) alimentaram novilhos com suplementação de 2.000 UI de vitamina E, por 67 dias, e obtiveram aumento na concentração de $\alpha$-tocoferol de 2,0 para $6,2 \mathrm{mg} \mathrm{g}^{-1}$ no músculo longissimus, o que mostra menor susceptibilidade do tecido muscular à oxidação lipídica e à oxidação da mioglobina da carne dos animais suplementados com vitamina E, em consequência da maior presença do $\alpha$-tocoferol. Não estão claras as razões pelas quais a suplementação com vitaminas não aumentou as concentrações de vitaminas $\mathrm{D}$ e E na carne das novilhas Canchim no presente trabalho. No entanto, como a restrição alimentar não influenciou negativamente a coloração e a maciez da carne das novilhas, o efeito da suplementação pode ter sido minimizado. Da mesma forma, observou-se que mesmo animais jovens já apresentam carne com boa coloração e maciez.

Segundo Hammond (1956), após severa subnutrição de bovinos, a recuperação alimentar provoca aumento de tecido conjuntivo, com prejuízo para a maciez da carne. No entanto, a restrição alimentar, no presente trabalho, não foi tão severa a ponto de promover impacto negativo sobre a maciez da carne (Tabela 4). Essa pode ser uma das razões pelas quais o efeito da suplementação com vitaminas foi nulo.

Rentfrow et al. (2001) alimentaram novilhas com suplementação de altos níveis de vitamina $\mathrm{D}_{3}$, ou com mistura de vitamina $\mathrm{D}_{3}$ e vitamina $\mathrm{E}$, e reportaram elevação do cálcio sérico, sem que tenha havido alteração ou redução na força de cisalhamento. Montgomery et al. (2004b) trabalharam com novilhos tratados com $5 \times 10^{6} \mathrm{UI}$ de vitamina $\mathrm{D}_{3}$, pelo período de oito dias antes do abate, e relataram melhora na maciez da carne maturada por sete dias, por meio da avaliação da força de cisalhamento entre animais que receberam suplemento e o grupo controle. Os valores de força de cisalhamento encontrados no presente trabalho estão dentro do padrão de carnes consideradas macias, de acordo com Wheeler et al. (2002), pois, de acordo com os autores, índices de fragmentação miofibrilar maiores ou iguais a 60 , para o músculo longissimus, denotam carne muito macia. Com relação à mastigabilidade, a média foi maior para animais sem suplementação de vitaminas do que em animais que receberam suplementação, o que confirma os resultados obtidos para força de cisalhamento e índice de fragmentação miofibrilar, e mostra que a vitamina $\mathrm{D}_{3}$ não influenciou de forma positiva a maciez da carne no presente trabalho. No entanto, não estão claras as razões pelas quais a suplementação com vitaminas $\mathrm{D}$ e $\mathrm{E}$ diminuiu a maciez da carne das novilhas da raça Canchim, quando se esperava o oposto ou nenhum efeito, de acordo com estudos anteriores (Swanek et al., 1999; Rider Sell et al., 2004).

\section{Conclusões}

1. A restrição alimentar quantitativa, em fêmeas jovens da raça Canchim, pode ser utilizada em sistemas de confinamento, pois não afeta negativamente o desempenho, a deposição de gordura e as características de carcaça e carne das novilhas.

2. A suplementação com vitaminas $D$ e $E$ não melhora a qualidade da carne em novilhas jovens da raça Canchim, independentemente de elas terem sido submetidas ou não a períodos de restrição alimentar.

\section{Agradecimentos}

À Fundação de Amparo à Pesquisa do Estado de São Paulo, pelo apoio financeiro.

\section{Referências}

ALBRECHT, E.; TEUSCHER, F.; ENDER, K.; WEGNER, J. Growth- and breed-related changes of marbling characteristics in cattle. Journal of Animal Science, v.84, p.1067-1075, 2006.

ANUALPEC. Anuário da pecuária brasileira. São Paulo: Instituto FNP, 2011. 378p.

ARNOLD, R.N.; SCHELLER, K.K.;ARP, S.C.; WILLIAMS, S.M.; SCHAEFER, D.M. Visual and spectrophotometric evaluations of beef color stability. Journal of Food Science, v.57, p.518-520, 1992.

CHOAT, W.T.; KREHBIEL, C.R.; DUFF, G.C.; KIRKSEY, R.E.; LAURIAULT, L.M.; RIVERA, J.D.; CAPITAN, B.M.; WALKER, D.A.; DONART, G.B.; GOAD, C.L. Influence of grazing dormant native range or winter wheat pasture on subsequent finishing cattle performance, carcass characteristics, and ruminal metabolism. Journal of Animal Science, v.81, p.3191-3201, 2003. 
CORNELL NET CARBOHYDRATE AND PROTEIN SYSTEM. The net carbohydrate and protein system for evaluating herd nutrition and nutrients excretion. Version 5.0. Ithaca: CNCPS, 2000. 237p.

GOERING, H.K.; VAN SOEST, P.J. Forage fiber analysis. Washington: USDA, 1970. 19p. (USDA. Agricultural handbook, 379).

GREINER, S.P.; ROUSE, G.H.; WILSON, D.E.; CUNDIFF, L.V.; WHEELER, T.L. The relationship between ultrasound measurements and carcass fat thickness and longissimus muscle area in beef cattle. Journal of Animal Science, v.81, p.676-682, 2003.

HAMMOND, J. Farm animals: their breeding, growth and inheritance. London: Edward Arnold, 1956. 322p.

HORWITZ, W. (Ed.). Official methods of analysis of AOAC international. $18^{\text {th }} \mathrm{ed}$. Arlington: Association of Official Analytical Chemists, 2006. 3000p.

JENKINS, K.H.; VASCONCELOS, J.T.; HINKLE, J.B.; FURMAN, S.A.; MELLO JUNIOR, A.S.; SENARATNE, L.S.; POKHAREL, S.; CALKINS, C.R. Evaluation of performance, carcass characteristics, and sensory attributes of beef from finishing steers fed field peas. Journal of Animal Science, v.89, p.1167-1172, 2011

KERTH, C.R.; MONTGOMERY, J.L.; MORROW, K.J.; GALYEAN, M.L.; MILLER, M.F. Protein turnover and sensory traits of longissimus muscle from implanted and nonimplanted heifers. Journal of Animal Science, v.81, p.1728-1735, 2003.

LAWRENCE, T.L.J.; PEARCE, J. Some effects of wintering yearling beef cattle on different planes of nutrition. I. Live-weight gain, food consumption and body measurement changes during the winter period and the subsequent grazing period. Journal of Agricultural Science, v.63, p.5-21, 1964.

MILLEN, D.D.; PACHECO, R.D.L.; ARRIGONI, M.D.B.; GALYEAN, M.L.; VASCONCELOS, J.T. A snapshot of management practices and nutritional recommendations used by feedlot nutritionists in Brazil. Journal of Animal Science, v.87, p.3427-3439, 2009.

MONTGOMERY, J.L.; GALYEAN, M.L.; HORST, R.L.; MORROW JUNIOR, K.J.; BLANTON JUNIOR, J.R.; WESTER, D.B.; MILLER, M.F. Supplemental vitamin D3 concentration and biological type of beef steers. I. Feedlot performance and carcass traits. Journal of Animal Science, v.82, p.2050-2058, 2004a.
MONTGOMERY, J.L.; KING, M.B.; GENTRY, J.G.; BARHAM, A.R.; BARHAM, B.L.; HILTON, G.G.; BLANTON JUNIOR, J.R.; HORST, R.L.; GALYEAN, M.L.; MORROW JUNIOR, K.J.; WESTER, D.B.; MILLER, M.F. Supplemental vitamin D3 concentration and biological type of beef steers. II. Tenderness, quality, and residues of beef. Journal of Animal Science, v.83, p.2092-2104, 2004b.

REINHARDT, C.D.; BUSBY, W.D.; CORAH, L.R. Relationship of various incoming cattle traits with feedlot performance and carcass traits. Journal of Animal Science, v.87, p.3030-3042, 2009.

RENTFROW, G.K.; BERGER, L.; CARR, T.; MCKEITH, F.; BREWER, M.S.; BERG, E.P. The effects of feeding elevated levels of vitamins $\mathrm{D}_{3}$ and $\mathrm{E}$ on beef longissimus tenderness. Journal of Animal Science, v.79, p.56, 2001. Supplement 2.

RIDER SELL, N.; MIKEL, W.B.; XIONG, Y.L.; BEHRENDS, J.M. Vitamin D3 supplementation of cull cows: effects on longissimus and semitendinosus muscle tenderness. Journal of Animal Science, v.82, p.225-230, 2004.

RYAN, W.J. Compensatory growth in cattle and sheep. Nutrition Abstracts and Reviews. Series B, v.50, p.653-664, 1990.

SAINZ, R.D.; DE LA TORRE, F.; OLTJEN, J.W. Compensatory growth and carcass quality in growth-restricted and refed beef steers. Journal of Animal Science, v.73, p.2971-2979, 1995.

SAS INSTITUTE. SAS user's guide: statistics. Version 5. Cary: SAS Institute, 2003.

STARKE, A.; HAUDUM, A.; BUSCHE, R.; BEYERBACH, M.; DANICKE, S.; REHAGE, J. Technical note: analysis of total lipid and triacylglycerol content in small liver biopsy samples in cattle. Journal of Animal Science, v.88, p.2741-2750, 2010.

SWANEK, S.S.; MORGAN, J.B.; OWENS, F.N.; GILL, D.R.; STRASIA, C.A.; DOLEZAL, H.G.; RAY, F.K. Vitamin $\mathrm{D}_{3}$ supplementation of beef steers increases longissimus tenderness. Journal of Animal Science, v.77, p.874-881, 1999.

UNITED STATES DEPARTMENT OF AGRICULTURE. Official United States standards for grades of carcass beef. Washington: USDA, 1989.

WHEELER, T.L.; VOTE, D.; LEHESKA, J.M.; SHACKELFORD, S.D.; BELK, K.E.; WULF, D.M.; GWARTNEY, B.L.; KOOHMARAIE, M. The efficacy of three objective systems for identifying beef cuts that can be guaranteed tender. Journal of Animal Science, v.80, p.3315-3327, 2002.

Recebido em 15 de dezembro de 2010 e aprovado em 1ํ de agosto de 2011

Pesq. agropec. bras., Brasília, v.46, n.8, p.920-927, ago. 2011 